\title{
Proceso de elaboración de yogur deslactosado de leche de cabra
}

\author{
Processo para elaboração de iogurte deslactosado de leite de cabra
}

\author{
Virginia Antonieta RODRIGUEZ ${ }^{1 \star}$, Bautista Fermín CRAVERO ${ }^{1}$, Armonía ALONSO$^{1}$
}

\begin{abstract}
Resumen
El objetivo de este trabajo fue desarrollar un proceso para la elaboración de yogur deslactosado de leche de cabra, realizando en forma simultánea la hidrólisis de la lactosa y la fermentación. Se utilizaron tres dosis de una $\beta$-galactosidasa ácida de origen fúngico (Aspergillus oryzae): 1253, 2506 y 3759 unidades/L, usando como referente una muestra sin enzima. Luego de una incubación de 5 horas a $38^{\circ} \mathrm{C}$ y posterior conservación durante 24 horas a $4^{\circ} \mathrm{C}$, se determinaron las concentraciones de glucosa, galactosa, lactosa, $\mathrm{pH}$ y acidez titulable. Teniendo en cuenta una concentración de lactosa en leche de 4,42 g. $100 \mathrm{~mL}^{-1}$, el mayor porcentaje de hidrólisis obtenido en el yogur $(82,6 \%$, p < 0,0001) se logró con 2506 unidades/L de enzima, mientras que sin el agregado de enzima fue de 48,5\%. Se concluye que el proceso utilizado permitiría, en una sola etapa, la elaboración de un yogur que además de tener las propiedades hipoalergénicas y nutricionales propias de la leche de cabra, por su bajo contenido en lactosa se convertiría en un alimento de características funcionales de gran utilidad y protagonismo para aquellas personas que padecen intolerancia al azúcar de la leche.

Palabras-clave: Aspergillus oryzae; $\beta$-galactosidasa; leche de cabra; yogur deslactosado.
\end{abstract}

\section{Resumo}

O objetivo deste trabalho foi desenvolver um processo para a elaboração de iogurte deslactosado de leite de cabra, realizando de forma simultânea a hidrólise da lactose e a fermentação. Utilizaram-se três doses de uma $\beta$-galactosidase ácida de origem fúngica (Aspergillus oryzae): 1253, 2506 e 3759 unidades/L, usando como referente uma amostra sem enzima. Após uma incubação de 5 horas a $38{ }^{\circ} \mathrm{C}$ e posterior conservação durante 24 horas a $4{ }^{\circ} \mathrm{C}$, determinaram-se as concentrações de glicose, galactose, lactose, pH e acidez titulável. Considerando uma concentração de lactose em leite de 4,42 g.100 mL $\mathrm{m}^{-1}$, a maior porcentagem de hidrólise obtida no iogurte $(82,6 \%, \mathrm{p}<0,0001)$ foi conseguida com 2506 unidades/L de enzima, enquanto que sem o agregado de enzima a porcentagem foi de $48,5 \%$. Conclui-se que o processo utilizado permitiria, somente numa etapa, a elaboração de um iogurte que além de ter as propriedades hipoalergênicas e nutricionais próprias do leite de cabra, por seu baixo conteúdo de lactose, se converteria num alimento de características funcionais de grande utilidade para aquelas pessoas que padecem intolerância ao açúcar do leite.

Palavras-chave: Aspergillus oryzae; $\beta$-galactosidase; leite de cabra; iogurte deslactosado.

\section{Introducción}

Las propiedades nutracéuticas e hipoalergénicas de la leche de cabra han hecho que la leche y sus derivados reciban en los últimos años mayor atención mundial y nacional. Actualmente la leche es consumida por más del $50 \%$ de la población mundial (CHACÓN VILLALOBOS, 2005; GILBERE; HOM, 2002).

La creciente demanda en el mercado de productos de origen caprino, sustenta la posibilidad de que la producción e industrialización de la leche se vea proyectada como un nicho esencial dentro del sector de la industria lechera internacional y nacional.

En Argentina, promover su producción e industrialización tiene la posibilidad de resolver tanto problemas vinculados con la salud y la nutrición como también sociales y económicos. Estos últimos, debido a que los productores caprinos son por lo general, familias de pocos recursos económicos y bajo nivel cultural, no tienen la propiedad de la tierra en la que se asientan $\mathrm{y}$ aunque sean propietarios, sus ingresos anuales son muy bajos (MAUBECÍN, 1990).
La leche caprina y sus productos derivados, principalmente quesos y yogur, están cobrando gran importancia dentro de la alimentación y salud humanas (BABAYAN, 1981; HAENLEIN, 1992; NUTTING et al., 1991; WHITE et al., 1991); pero su demanda se debe fundamentalmente a la potencialidad que tienen de sustituir los lácteos de origen bovino en la dieta.

Existe un alto porcentaje de niños, que al consumir leche bovina presentan reacciones adversas, ya sean debido a hipersensibilidad (base inmunológica) como la alergia a las proteínas o la intolerancia a la lactosa; aunque esta última se presenta con mayor frecuencia en personas adultas.

En leche caprina los valores de $\alpha$ s1-caseína son muy bajos y en algunos casos esta fracción está ausente, dependiendo del tipo genético (HAENLEIN, 1998; JENNESS, 1980), lo que hace que la $\beta$-caseína sea cuantitativamente la proteína principal.

La fracción $\alpha$ s1-caseína es una de las principales responsables de respuestas inmunológicas perjudiciales en niños,

Recebido para publicação em 29/4/2007

Aceito para publicação em 20/3/2008 (002494)

${ }^{1}$ Facultad de Ciencias Agropecuarias, Universidad Nacional de Córdoba - UNC, Av. Valparaiso y Rogelio Martínez, Ciudad Universitaria, CC 509, CP 5000, Córdoba,

Argentina, E-mail: virodrig@agro.uncor.edu

${ }^{*}$ A quem a correspondência deve ser enviada 
como eczemas, urticaria, rinitis, asma, bronquitis, diarreas, reacciones conocidas como alergia a las proteinas de la leche de vaca (GREZESIAK, 1989; MAREE, 1978).

Por otra parte, influye en la tensión del cuajo a nivel gástrico. Una baja cantidad de $\alpha$ s1-caseína genera una estructura altamente hidratada, más abierta y menos firme. Esto facilita la digestión del coágulo, experimentando un menor tiempo de tránsito gástrico (HAENLEIN, 2002; VEGA Y LEÓN et al., 2005).

La mayor velocidad del pasaje gástrico sería una de las razones por la cual la lactosa de la leche de cabra causaría menos problemas de intolerancia al no haber tiempo suficiente para una acentuada fermentación en el colon (BOYAZOGLU; MORAND-FEHR; 2001; HAENLEIN, 2002; RICHARDSON, 2004).

La intolerancia a la lactosa se presenta como resultado de una deficiencia de $\beta$-galactosidasa o lactasa, enzima ubicada en el borde superior de las microvellosidades del intestino delgado. Esta enzima produce la hidrólisis de la lactosa en glucosa y galactosa, monosacáridos fácilmente absorbidos por transporte activo.

La actividad de la lactasa permanece en niveles altos durante la primera parte de la niñez (salvo ausencia por causas genéticas) y luego declina a valores muy bajos en la adultez. La caída de la actividad de la lactasa, que lleva a una mala digestión de la lactosa, ocurre desde la niñez a la adultez y es un patrón fisiológico normal en el 75-90\% de la población adulta mundial (PEUHKURI, 2000; RENNER, 1997; SAHI, 1994). Si la actividad de la lactasa es muy baja en relación a la cantidad de lactosa ingerida, ésta no puede ser totalmente hidrolizada y una cantidad considerable de la misma llega al colon. Esto produce síntomas clínicos persistentes tales como: diarrea, distensión abdominal, dolor, borborigmos y flatulencias; síndrome comúnmente referido como intolerancia a la lactosa (PEUHKURI, 2000; VEITH, 2004; VESA; MARTEAU; KORPELA, 2000).

El interés que recibe esta problemática, desde el punto de vista nutricional, es que priva a aproximadamente al 75\% de la población adulta en el mundo (SUAREZ; SAVAIANO; LEVITT, 1995; VESA; MARTEAU; KORPELA, 2000) la ingesta de varios productos lácteos que son una excelente fuente de calcio y proteínas de alta calidad, como así también de otros minerales y vitaminas.

Sin embargo, se observó que la población con un alto índice de deficiencia de lactasa y que consumía leches fermentadas reducía la sintomatología.

A partir de la década del 70, se sugiere que el yogur podría ayudar a mejorar la intolerancia a la lactosa. Actualmente, uno de sus efectos probióticos más consistentes y reproducibles, es la disminución de los síntomas asociados con la mala digestión de la lactosa. La liberación de la lactasa contenida en las células del fermento, cuando éstas llegan al intestino, sería una de las razones posibles por las cuales el consumo de yogur mejora la digestión de la lactosa (BAER, 1970; De VRESE; KELLER; BARTH, 1992; De VRESE et al., 2001; GENDREL et al., 1990; GILLILAND; KIM, 1984; KOLARS et al., 1984; MARTEAU et al., 1990; MARTINI et al., 1987; POCHART et al., 1989; SHERMAK et al., 1995).

No obstante, la persistencia de malestares gastrointestinales luego de consumir yogur, indicarían que la cantidad de $\beta$-galactosidasa del cultivo no siempre es suficiente para atenuar los síntomas de la mala digestión (DEWIT; POCHART; DESLEUX, 1988; KOLARS et al., 1984; MARTEAU et al., 1990).

Esto conlleva a la necesidad de introducir mejoras en este producto, como lo es la reducción de su contenido en lactosa mediante la utilización de lactasas exógenas.

En Argentina, aún no existen en el mercado yogures deslactosados. En algunos países de América Latina, como Costa Rica y Colombia, además de producir "leche deslactosada", actualmente tienen en el mercado una línea de "yogures deslactosados” (MUNDO LÁCTEO Y CÁRNICO, 2005).

Estos son elaborados exclusivamente a partir de leche de vaca a la que se le ha hidrolizado parcialmente la lactosa, antes de la etapa de fermentación.

El procedimiento del deslactosado, consiste en colocar la leche pasteurizada con la enzima en silos de almacenamiento, a una temperatura entre $6-10{ }^{\circ} \mathrm{C}$ para contrarrestar el desarrollo de la flora residual. Como este rango de temperatura se encuentra lejos del óptimo de la actividad correspondiente a la $\beta$-galactosidasa del Kluyveromyces spp. $\left(35-40^{\circ} \mathrm{C}\right)$, enzima habitualmente utilizada en la industria láctea, el proceso insume entre 15 y 20 horas para lograr aproximadamente un $85 \%$ de hidrólisis (REPELIUS, 2001).

Además de la desventaja del tiempo y el equipamiento necesarios, está la calidad microbiológica de la leche. Si bien existe un tratamiento térmico de la leche antes de la elaboración del yogur, un eventual crecimiento de bacterias psicrófilas y psicrotrofas durante el proceso de deslactosado puede afectar, a través de sus enzimas termorresistentes (lipasas y proteasas), las características sápido-aromáticas del yogur elaborado.

Los objetivos de este trabajo fueron: 1) Obtener un yogur deslactosado utilizando leche de cabra, para incrementar sus características nutracéuticas; e 2) Realizar en forma simultánea la fermentación y la hidrólisis de la lactosa con la finalidad de reducir el tiempo empleado y el equipamiento necesario en la elaboración del producto.

Para implementar la hidrólisis y la fermentación en una misma etapa, hubo que seleccionar una $\beta$-galactosidasa diferente a las de uso tradicional (Kluyveromyces spp.).

La temperatura y el $\mathrm{pH}$ óptimos de las $\beta$-galactosidasas varían según el origen, aunque la especificidad es esencialmente la misma. Las de uso comercial se encuentran dentro de dos grupos: "ácidas" y "neutras". Las “ácidas" presentan una actividad óptima a un $\mathrm{pH}$ entre 3 y 5 y una temperatura entre 46 y $55^{\circ} \mathrm{C}$, mientras que las condiciones para las "neutras" son un rango de $\mathrm{pH}$ de 6,5 y 7,3 y una temperatura entre 35 y $40{ }^{\circ} \mathrm{C}$. Generalmente las enzimas producidas por levaduras son consideradas neutras y las obtenidas a partir de hongos, ácidas. 
El Kluyveromyces lactis es la levadura que produce la lactasa más ampliamente usada en la industria láctea para hidrolizar la lactosa de la leche, mientras que los Aspergillus oryzae y niger producen una lactasa ácida, con un $\mathrm{pH}$ óptimo de 5 y 3,5, respectivamente, que es la más utilizada en la industria para deslactosar el suero de queso (HOLSINGER; KLIGERMAN, 1991; ZADOW, 1984).

Debido a que el $\mathrm{pH}$ de la $\beta$-galactosidasa producida por el Aspergillus oryzae se ajusta más a las condiciones de acidez del proceso fermentativo, se eligió a esta enzima para desarrollar el yogur deslactosado.

\section{Material y métodos}

Se utilizó leche de cabras cruza Anglo-nubian x Criolla proveniente de un tambo ubicado en la zona de Malagueño (Lat. -31,46, Long. -64,36, $589 \mathrm{msnm}$ ) provincia de Córdoba, Argentina. De la leche mezcla de tanque, se extrajo una cantidad suficiente para cubrir los ensayos de laboratorio previstos durante la etapa experimental. Para su caracterización se utilizaron los siguientes métodos: Proteínas totales: \% Nitrógeno total x 6,38 (Kjeldahl), Grasa (Gerber), Lactosa (método enzimático Lactose/d-galactose test, Boehringer Mannheim/R-Biopharm), Sólidos Totales (desecación en estufa a $102-105^{\circ} \mathrm{C}$ hasta peso constante), Cenizas (incineración en mufla a $500{ }^{\circ} \mathrm{C}$ ), $\mathrm{pH}$ (peachímetro TOA HM30V), Acidez titulable (método Dörnic) y Descenso Crioscópico (Crióscopo Advanced 4D3).

Se estandarizó el contenido graso de la leche a $3 \%$ y se fraccionó el volumen obtenido en un número de alícuotas de $150 \mathrm{~mL}$, tal que permitieran tres repeticiones completas de cada experimento. Estas muestras se conservaron a $-40^{\circ} \mathrm{C}$ para que la calidad composicional de la leche fuese la misma durante todo el desarrollo del trabajo experimental, ya que es afectada por la etapa de lactancia y época del año, entre otros factores.

Se utilizó un fermento liofilizado DVS ("Direct Vat Set"), el Yo-flex YC-180 de Chr. Hansen. Este cultivo láctico termófilo está constituído por una mezcla definida de cepas que contiene: Streptococcus thermophilus, Lactobacillus delbruekii subesp. bulgaricus y Lactobacillus delbruekii subesp. lactis.

La enzima utilizada para la hidrólisis fue una $\beta$-galactosidasa ácida de origen fúngico, proveniente del Aspergillus oryzae (Lab. Sigma), cuyas características comerciales son: actividad de 9.400 unidades/g de enzima comercial, $\mathrm{pH}$ de 4,5 y temperatura de $30^{\circ} \mathrm{C}$, usando como sustrato la lactosa.

Las muestras de leche estandarizada recibieron un tratamiento térmico de $90{ }^{\circ} \mathrm{C}$ durante 5 minutos y se enfriaron rápidamente a $38^{\circ} \mathrm{C}$. Luego en forma simultánea se disolvieron, mediante agitación mecánica suave, el fermento y la enzima.

La cantidad de fermento sólido utilizado fue equivalente a un $2 \%$ de inoculación de fermento industrial activo y se utilizaron tres dosis de $\beta$-galactosidasa: 1253, 2506 y 3759 unidades/L $(\mathrm{U} / \mathrm{L})$, teniendo siempre como referencia una muestra sin agregado de lactasa externa.
Las muestras se incubaron en reposo a $38^{\circ} \mathrm{C}$ durante 5 horas en baño de agua termostatizado y se almacenaron en cámara frigorífica a $4{ }^{\circ} \mathrm{C}$ durante 24 horas.

El tiempo y la temperatura fijados para la fermentación se seleccionaron para compatibilizar las condiciones requeridas para el desarrollo de las cepas del fermento, la acción hidrolítica de la enzima, la textura y las características organolépticas del yogur.

El almacenamiento en frío luego de la elaboración, se realiza para evitar una sobreacidificación y mejorar la producción de aromas, consistencia y textura. Por otra parte, entre 24 y 48 horas es el período de estacionamiento en cámara frigorífica que se utiliza habitualmente en la industria, antes de que el producto fermentado salga a la venta.

Al cabo de las 24 horas de almacenamiento, se tomaron dos muestras de cada uno de los yogures, previamente homogeneizados. En una se midieron el $\mathrm{pH}$ y la acidez titulable y en la otra, previa inactivación de la enzima mediante ebullición y el agregado de ácido tricloroacético, se determinaron las concentraciones de glucosa (método enzimático glucosa oxidasa - Wiener lab), galactosa y lactosa (método enzimático Lactose/d-galactose test, Boehringer Mannheim/R-Biopharm). El porcentaje de hidrólisis logrado en los distintos yogures se determinó considerando la lactosa residual en cada uno de ellos y el contenido de lactosa en la leche de partida (4,42\%). Para todas las variables se empleó el modelo de análisis de varianza unifactorial, excepto para $\mathrm{pH}$, que se analizó mediante el test de Kruskal Wallis. Cuando el ANAVA detectó diferencias significativas $(\alpha=0,05)$ entre los diferentes tratamientos, se usó el test de LSD para evaluar las diferencias entre las medias de las variables.

Previo a la elaboración de los diferentes yogures, se determinó el efecto de la dosis de enzima sobre la velocidad de acidificación. Para ello se incubaron muestras sin enzima y con el agregado de 1253 y 2506 U/L de enzima y se tomaron muestras a intervalos de una hora midiéndose el $\mathrm{pH}$ y la acidez titulable $\left({ }^{\circ} \mathrm{D}\right)$. Los resultados se analizaron mediante análisis de varianza (ANAVA) de medidas repetidas en el tiempo. Luego del ANAVA se realizó un test de comparaciones múltiples (LSD) para analizar las diferencias significativas $(\alpha=0,05)$.

\section{Resultados y discusión}

\subsection{Materia prima}

La composición media y los parámetros físico-químicos de la leche de cabra utilizada en la elaboración de yogur fueron: Proteínas totales: 4,55 \pm 0,04\%, Grasa: 3,00 \pm 0,1\% Lactosa: $4,42 \pm 0,04 \%$, Sólidos Totales: $12,61 \pm 0,06 \%$, Cenizas: $0,68 \pm 0,06 \%$, Acidez titulable: $17,90 \pm 0,25^{\circ} \mathrm{D}, \mathrm{pH}: 6,65 \pm 0,02$ y Descenso Crioscópico: $0,567 \pm 0,01^{\circ} \mathrm{C}$.

La leche contenía inicialmente $4,6 \%$ de grasa, pero se descremó para lograr un tenor graso del 3,00\%. El propósito de estandarizar este parámetro fue lograr un índice proteína/ grasa mayor a uno, condición que mejora notablemente las características reológicas del coágulo. 


\subsection{Curvas de acidificación}

Se realizaron curvas de acidificación (Figura 1) para determinar si la dosis de enzima podía afectar la velocidad de fermentación del yogur. Se ensayaron dos dosis de $\beta$-galactosidasa (1253 y $2506 \mathrm{U} / \mathrm{L}$ ), teniendo siempre como referencia una muestra sin agregado de enzima.

Como puede observarse en la Figura 1, los valores de $\mathrm{pH}$ fueron menores $(\mathrm{p}<0,05)$ para las muestras con enzima sólo en las tres primeras horas, no existiendo diferencias entre las dosis agregadas.

Por otra parte, la acidez titulable fue afectada significativamente $(\mathrm{p}<0,05)$ por el agregado de $\beta$-galactosidasa, durante todo el proceso fermentativo salvo en la primera hora. También fue influenciada por la dosis de enzima aplicada, como puede observarse en la tercera y cuarta hora, donde la dosis mayor genera mayor acidez $(\mathrm{p}<0,05)$. Es importante destacar, que esta marcada diferencia entre las dosis y con la muestra sin enzima se logró, cuando el pH de la fermentación se acercó al pH óptimo de la enzima fúngica, un $\mathrm{pH}$ alrededor de 5.

No obstante, se puede inferir que un aumento de la cantidad de $\beta$-galactosidasa, tan importante como el doble de la primera dosis ensayada, no produjo una mejora en la velocidad de fermentación, tal que justificara detener el proceso de elaboración antes de las cinco horas.

\subsection{Caracterización de los yogures terminados}

Los yogures elaborados con y sin enzima se almacenaron, luego de la fermentación, a $4{ }^{\circ} \mathrm{C}$ durante 24 horas, para evitar una sobreacidificación y consolidar sus texturas y características organolépticas.

Posterior al almacenamiento, se determinó la calidad de los yogures elaborados con tres diferentes dosis de $\beta$-galactosidasa: 1253,2506 y 3759 U/L y sin agregado de la misma. Dicha cali-

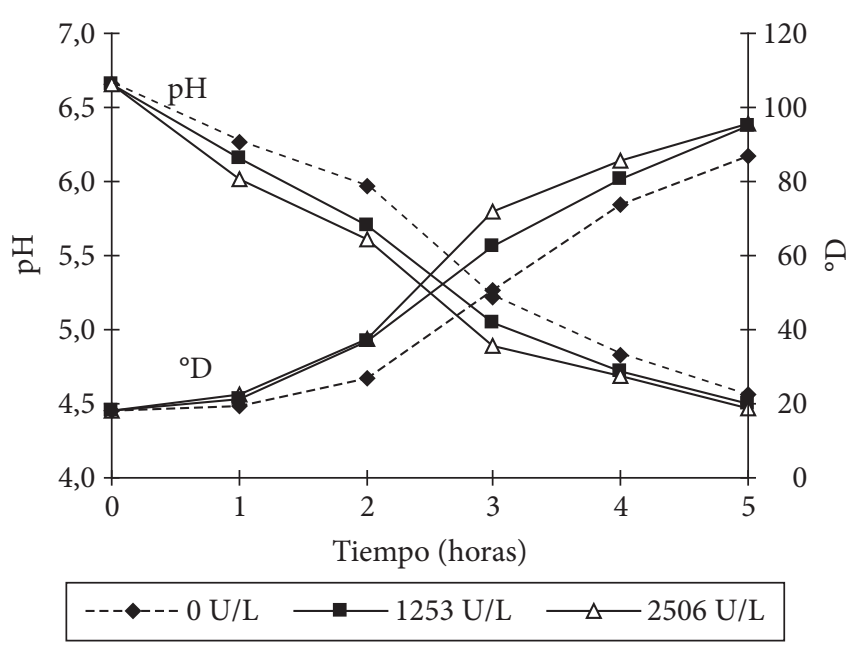

Figura 1. Efecto de la dosis de $\beta$-galactosidasa (1253 y $2506 \mathrm{U} / \mathrm{L}$ ) sobre la velocidad de fermentación, expresada en unidades de $\mathrm{pH}$ y acidez titulable $\left({ }^{\circ} \mathrm{D}\right)$. dad se estableció en función de las concentraciones de lactosa, galactosa y glucosa (Figura 2), como así también del porcentaje de hidrólisis total (Figura 3), acidez titulable (Figura 4) y pH, encontrados en cada uno de ellos. El comportamiento de estos dos últimos parámetros no fue concordante. Mientras que en la acidez titulable hubo diferencias $(\mathrm{p} \leq 0,05)$ entre tratamientos, los valores de $\mathrm{pH}$ no se diferenciaron estadísticamente, pudiendo expresarse una media de 4,51 $\pm 0,04$.

$\mathrm{Al}$ analizar el efecto de la dosis de enzima sobre la composición de azúcares (Figura 2), se encuentra que con el agregado de $2506 \mathrm{U} / \mathrm{L}$ se obtiene el menor contenido de lactosa residual $\left(0,77\right.$ g.100 mL $\left.\mathrm{m}^{-1}\right)$. Esta cantidad representa un porcentaje de hidrólisis del $82,6 \%$, valor significativamente $(\mathrm{p} \leq 0,05)$ mayor

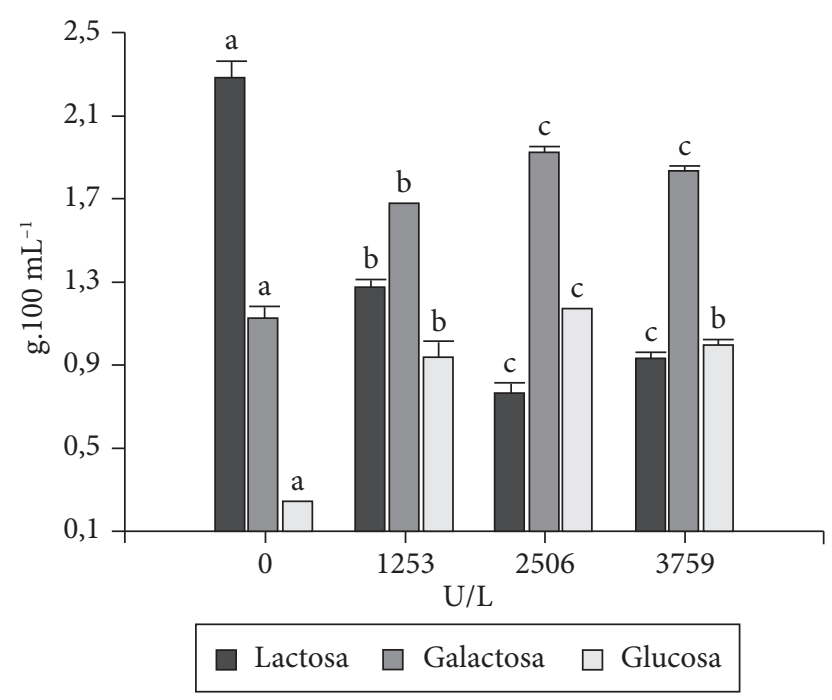

Figura 2. Concentraciones de lactosa, galactosa y glucosa $\left(\mathrm{g} .100 \mathrm{~mL}^{-1}\right)$ en yogures con distintas dosis de $\beta$-galactosidasa $(0,1253,2506$ y $3759 \mathrm{U} / \mathrm{L})$. Letras distintas indican diferencias significativas $(\mathrm{p} \leq 0,05)$ para cada componente entre tratamientos.

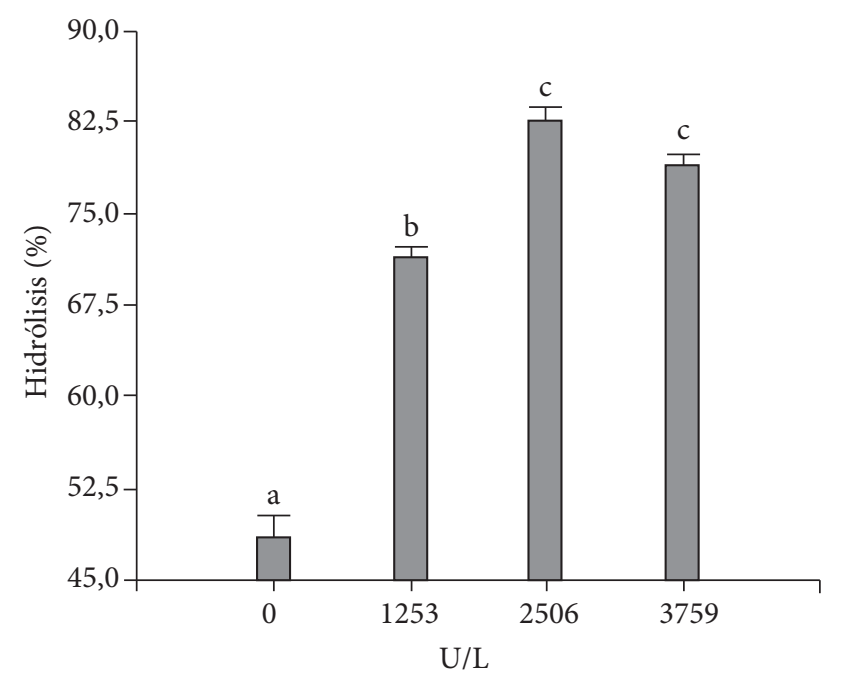

Figura 3. Porcentaje de hidrólisis de lactosa en yogures con distintas dosis de $\beta$-galactosidasa $(0,1253,2506$ y $3759 \mathrm{U} / \mathrm{L})$. Letras distintas indican diferencias significativas $(\mathrm{p} \leq 0,05)$. 


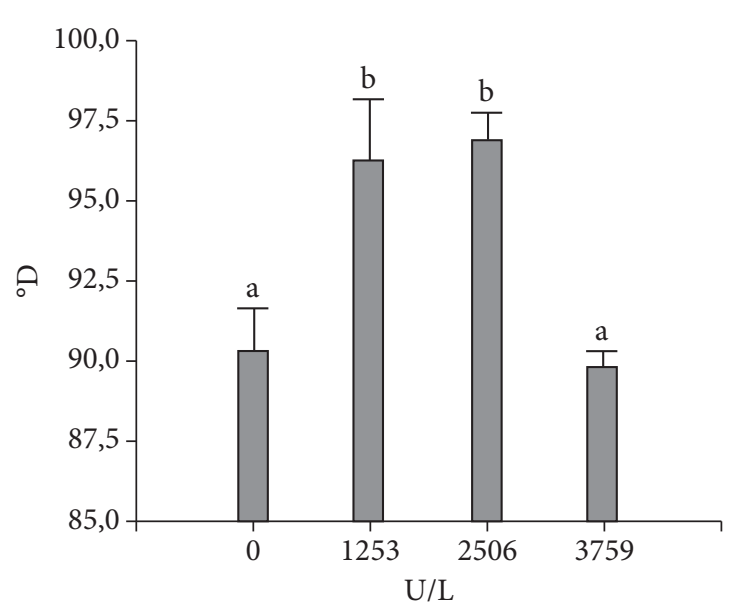

Figura 4. Valores de acidez titulable en yogures con diferentes dosis de $\beta$-galactosidasa $(0,1253,2506$ y $3759 \mathrm{U} / \mathrm{L})$. Letras distintas indican diferentecias significativas $(\mathrm{p} \leq 0,05)$.

al conseguido con la dosis de $1253 \mathrm{U} / \mathrm{L}$ y sin agregado de lactasa. Sin embargo, cuando se incrementó la cantidad de enzima a 3759 U/L no se produjo una mejora en la eficiencia hidrolítica (Figura 3). Esto demuestra que la dosis de 2506 U/L es la más conveniente para obtener el mayor grado de conversión de lactosa.

Uno de los factores más importantes, que limita el rendimiento de la $\beta$-galactosidasa, es la inhibición competitiva que ejercen los productos de reacción, glucosa y galactosa (BOON; JANSSEN; VAN'T RIET, 2000; DESCHAVANNE; VIRATELLE; YON, 1978; MATIOLI; FARIA de MORAES; ZANIN, 2003).

Durante el proceso de fermentación, los productos glucosa y galactosa, en especial esta última, van incrementando, mientras que el sustrato lactosa va decreciendo, lo que no sólo favorecería sino que acentuaría el efecto inhibitorio citado.

Entre los monosacáridos, la galactosa es el inhibidor más importante para la $\beta$-galactosidasa (DESCHAVANNE; VIRATELLE; YON, 1978), aunque la fuerza del poder inhibitorio depende del origen de la enzima. La $\beta$-galactosidasa del Aspergillus oryzae es más inhibida por este monosacárido que las provenientes del Kluyveromyces spp. (BOON; JANSSEN; VAN'T RIET, 2000).

En la Figura 2, se puede observar que la concentración de galactosa supera ampliamente a la de lactosa, para las dos dosis mayores de enzima. Si bien, estas son las concentraciones finales, no cabe duda que durante el proceso fermentativo la concentración relativa se iría haciendo cada vez más favorable para la galactosa con respecto a los otros dos azúcares. Como consecuencia de ello, ocuparía competitivamente el sitio activo de la $\beta$-galactosidasa, provocando la disminución de su actividad. Esto fue demostrado por Carminatti (2001) quien comparó el porcentaje de hidrólisis logrado en suero de leche usando $\beta$-galactosidasa del Kluyveromyces lactis (Maxilact L-5000), en un reactor con y sin membrana. La membrana permitía el permeado continuo de los productos de hidrólisis, mientras que de la otra manera la enzima permanecía conjuntamente con ellos. Cuando los productos eran retirados, se logró un $92 \%$ de hidrólisis, mientras que la presencia de ellos limitó el proceso a un $82 \%$.

Otro hallazgo semejante a nuestro trabajo fue que, de las tres dosis de enzima que ensayó, 400, 1250 y 2000 mg.L $\mathrm{L}^{-1}$, los porcentajes de hidrólisis obtenidos con 1250 y 2000 mg.L-1 fueron prácticamente idénticos y superiores en un $100 \%$ al obtenido con la menor dosis, considerando como dosis óptima a la de $1250 \mathrm{mg} . \mathrm{L}^{-1}$, ya que la cantidad superior a ésta no mejoraba la tasa de conversión y sólo disminuía en quince minutos el tiempo necesario para lograr el máximo rendimiento.

Si bien, la inhibición por producto tiene un efecto gravitacional sobre la actividad de la enzima, existirían otros factores como reversibilidad de la reacción, inhibición por constituyentes de la leche, transgalactosidación entre otros, que contribuirían a modificar la cinética (MATIOLI; FARIA de MORAES; ZANIN, 2003).

Otro aspecto que modificaría negativamente la eficiencia hidrolítica de la enzima, es que en la elaboración de nuestro yogur deslactosado, no se realiza una agitación permanente como la que normalmente se aplica en los procesos de hidrólisis, tanto de leche como de suero, para asegurar una adecuada mezcla de la enzima y mantener la homogeneidad del sistema. La incubación se realiza en el envase, obteniéndose un producto más firme conocido como yogur tradicional por su textura, donde el coágulo se mantiene íntegro. No obstante, independientemente del tipo de yogur que se elabore, firme o batido, la incubación se realiza en total estado de reposo.

La falta de agitación durante la fermentación y la viscosidad del producto desarrollado, impiden una buena dispersión de la $\beta$-galactosidasa, lo que imposibilitaría que a través del tiempo se encuentre con nuevas cantidades de sustrato (lactosa) que compitan y excluyan a los productos (galactosa) de reacción que se van concentrando en su entorno, limitando su actividad.

A pesar de las limitaciones expuestas, se obtiene un yogur con un contenido de lactosa residual menor a $1 \mathrm{~g} \%$. El bajo contenido en lactosa logrado, lo convierte en un producto apto para el consumo por personas intolerantes al azúcar de la leche, ya que reduciría sensiblemente la sintomatología (HERTZLER; HUYNH; SAVAIANO, 1996; HOLSINGER; KLIGERMAN, 1991).

Por otra parte, la utilización de leche de cabra le otorga al yogur desarrollado, un valor agregado extra, porque reuniría las características hipoalergénicas y nutricionales propias de la leche de cabra.

\section{Conclusiones}

El proceso de elaboración propuesto permite obtener un yogur con un contenido de lactosa menor a $1 \mathrm{~g} \%$. Esto lo convierte en un alimento adecuado para el consumo de personas que padecen de intolerancia al azúcar de la leche.

La utilización de la leche de cabra le confiere un valor nutricional adicional debido a las características nutracéuticas e hipoalergénicas de la misma. 
La hidrólisis de la lactosa y la fermentación realizadas en forma simultánea, tienen como ventajas la disminución del tiempo empleado y del equipamiento necesario para el desarrollo del producto.

\section{Agradecimientos}

Se agradece a la Ingeniera Agrónoma María Gabriela Molina, su colaboración en el análisis estadístico de los datos.

\section{Referencias}

BABAYAN, V. K. Medium chain length fatty acid esters and their medical and nutritional applications. Journal of the American Oil Chemist's Society, v. 58, n. 1, p. 49-50, 1981.

BAER, D. Lactase deficiency and yogurt. Social Biology, v. 17, n. 1, p. 143-147, 1970.

BOON, M. A.; JANSSEN, A. E. M.; VAN'T RIET, K. Effect of temperature and enzyme origen on the enzymatic synthesis of oligosaccharides. Enzyme and Microbial Techonology, v. 26, n. 2-4, p. 271-281, 2000.

BOYAZOGLU, J.; MORAND-FEHR, P. Mediterranean dairy sheep and goat products and their quality. A critical review. Small Ruminant Research, v. 40, n. 1, p. 1-11, 2001.

CARMINATTI, C. A. Ensaios de hidrolise enzimatica da lactose em reator a membrana utilizando $\beta$-galactosidase Kluyveromyces lactis. Florianópolis, 2001, 79p. Dissertaçao - (Mestre em Engenharia Quimica), Centro Tecnologico-Dpto.de e Engenharia de Alimentos, Universidad Federal de Santa Catarina. Disponivel em: <http://www2.enq.ufsc.br/teses/m076.pdf>. Acesso: 10 Jun. 2006.

CHACÓN VILLALOBOS, A. Aspectos nutricionales de la leche de cabra (capra hircus) y sus variaciones en el proceso agroindustrial. Agronomía Mesoamericana, v. 16, n. 2, p. 239-252, 2005.

DE VRESE, M.; KELLER, B.; BARTH, C. A. Enhancement of intestinal hydrolysis of lactose by microbial b-galactosidase (EC 3.2.1.23) of kefir. British Journal of Nutrition, v. 67, n. 1, p. 67-75, 1992.

DE VRESE, M. et al. Are viable microorganisms essential for the enhancement of intestinal hydrolysis of lactose by the Beta-galactosidase of fermented milk products?. American Journal of Clinical Nutrition, v. 73, (suppl.), p. 490S, 2001.

DESCHAVANNE, P. J.; VIRATELLE, O. M.; YON, J. M. Conformational adaptability of the active site of $\beta$-galactosidase. Journal of Biological Chemistry, v. 253, n. 3, p. 833-837, 1978.

DEWIT, O.; POCHART, P.; DESLEUX, J. F. Breath hydrogen concentration after lactose, milk, fresh or heated yogurt ingestion by healthy young adults with or without lactose malabsorption. Nutrition, v. 4, n. 2, p. 131, 1988.

GENDREL, D. et al. Utilisation d'un lait fermenté en poudre chez lenfant malnutri ou intolérant au lactose. Presse Médicale, v. 19, n. 10, p. 700-704, 1990.

GILBERE, G.; HOM, D. A. The magic of goat milk. 2002 . Disponivel em: <http://fredompressonline/FPO_feacturedArticles_carpa. htm>. Acesso: 16 nov. 2004.

GILLILAND, S. E.; KIM, H. S. Effect of viable starter culture bacteria on lactose utilization in humans. Journal of Dairy Science, v. 67, n. 1, p. 1-6, 1984.

GREZESIAK, T. Prescription of goat milk in pediatrics revolutionary? Le Concours Medical, v. 111, p. 3059-3064, 1989.

HAENLEIN, G. F. W. Role of goat meat and milk in human nutrition. In: International Conference of Goats, 5, 1992. Proceedings... New
Delhi: Indian Council Agricultural Reseach, 1992, v. 2, parte II, p. $575-580$.

HAENLEIN, G. F. W. The value of goat and sheep to sustain mountain farmers. International Journal of Animal Science, v. 13, p. 187-194, 1998.

HAENLEIN, G. F. W. Lipids and proteins in milk, particularly goat milk. 2002. Disponivel em: <http://ag.udel.edu/extension/ information/goatmgt/gm-08.htm>. Acesso em: 28 oct. 2002.

HERTZLER, S. R.; HUYNH, B. C. L.; SAVAIANO, D. A. How much lactose is low lactose. Journal of the American Dietetic Association, v. 96, n. 3, p. 243-246, 1996.

HOLSINGER, V. H.; KLIGERMAN, A. E. Applications of lactase in dairy foods and other foods containing lactose. Food Technology, v. 45, n. 1, p. 93-95, 1991.

JENNESS, R. Composition and characteristics of goat milk: Review 1968-1979. Journal of Dairy Science, v. 63, n. 10, p. 1605-1630, 1980.

KOLARS, J. C. et al. Yogurt an autodigesting source of lactose. New England Journal of Medicine, v. 310, n. 1, p. 1-3, 1984.

MAREE, H. P. Goat milk an use as hypo-allergenic infant food. Dairy Goat Journal, v. 56, n. 5, p. 62-65, 1978.

MARTEAU, P. et al. Effect of the microbial lactase (EC 3.2.1.23) activity in yoghurt on the intestinal absorption of lactose: an in vivo study in lactase-deficient humans. British Journal of Nutrition, v. 64, n. 1, p. 71-79, 1990.

MARTINI, M. C. et al. Lactose digestion by yogurt $\beta$-galactosidase: influence of $\mathrm{pH}$ and microbial cell integrity. American Journal of Clinical Nutrition, v. 45, p. 432-436, 1987.

MATIOLI, G.; FARIA DE MORAES, F.; ZANIN, G. Operational stability and kinetics of hydrolysis by $\beta$-galactosidase from Kluyveromyces fragilis. Acta Scientiarum. Health Sciences, v. 25, n. 1, p. 7-12, 2003.

MAUBECÍN, R. Producción caprina. Argentina: Ed. R. Maubecín, 1990.

MUNDO LÁCTEO Y CÁRNICO. Yogurt deslactosado: proceso y ventajas. 2005. Disponivel em: http://www.alimentariaonline.com/ desplegar_nota.asp?did=1269. Acesso em: 20 May. 2006.

NUTTING, C. W.; ISLAM, S.; DAUGIRDAS, J. T. Vasorelaxant effects of short chain fatty acid salts in rat caudal artery. American Journal of Physiology, n. 261, p. 561-567, 1991.

PEUHKURI, K. Lactose, lactase, and bowel dissorders. Dissertação - (Doutorado em Medicina), Faculty of Medicine, Institute of Biomedicine, Helsinki, 2000. Disponivel em: <http://ethesis. helsinki.fi>. Acesso em: 5 Ago. 2004.

POCHART, P. et al. Viable starter culture, B-galactosidase activity, and lactose in duodenum after yogurt ingestion in lactase-deficient humans. American Journal of Clinical Nutrition, v. 49, p. 828-831, 1989.

RENNER, E. Efectos de la dieta sobre la digestión de lactosa. Food Science and Technology International, v. 3, n. 2, p. 71-79, 1997.

REPELIUS, C. Lactase: an optimun enzime for low lactose. Asia Pacific Industry, Special Supplement Ingredient \& Additives, jun. 2001.

RICHARDSON, C. W. Let's learn about dairy goats and goat's milk. 2004. Oklahoma: Cooperative Extensión Service, Oklahoma State University. (Boletin No 424).

SAHI, T. Genetics and epidemiology of adult-type hypolactasia. Scandinavian Journal of Gastroenterology, v. 29, suppl. 202, p. 1-20, 1994. 
SHERMAK, M. A et al. Effect of yogurt on symptoms and kinetics of hydrogen production in lactose-malabsorbing children. American Journal of Clinical Nutrition, v. 62, p. 1003-1006, 1995.

SUAREZ F. L.; SAVAIANO, D. A.; LEVITT, M. D. Review article: the treatment of lactose intolerance. Alimentary Pharmacology \& Therapeutics, v. 9, n. 6 p. 589-597, 1995.

VEGA Y LEÓN, S. et al. Leche de cabra: producción, composición y aptitud industrial. Revista Carnilac Industrial. 2005. Disponible en: <http://www.alfa-editores.com/canilac.htm>. Acesso em: 16 Oct. 2005.
VEITH, W. Lactose Intolerance-Scientific Perspectives. 2004. Disponivel em: <http://www.amazingdiscoveries.org/health_ lactose.htm>. Acesso em: 4 Ago. 2004.

VESA, T. H.; MARTEAU, P.; KORPELA, R. Lactose intolerance. Journal of the American College of Nutrition, v. 19, (Suppl. 2), p. 165S-175S, 2000.

WHITE, R. P. et al. Identification of capric acid as a potent vasorelaxant of human basilar arteries. Stroke, v. 22, n. 4, p. 469-476, 1991.

ZADOW, J. G. 1984. Lactose: Properties and uses. Journal of Dairy Science, v. 67, n. 11, p. 2654-2679, 1984. 